\title{
In silico modification of suberoylanilide hydroxamic acid (SAHA) as potential inhibitor for class II histone deacetylase (HDAC)
}

\author{
Usman SF Tambunan*, N Bramantya, Arli A Parikesit \\ From Asia Pacific Bioinformatics Network (APBioNet) Tenth International Conference on Bioinformatics - First \\ ISCB Asia Joint Conference 2011 (InCoB2011/ISCB-Asia 2011) \\ Kuala Lumpur, Malaysia. 30 November - 2 December 2011
}

\begin{abstract}
Background: The cervical cancer is the second most prevalent cancer for the woman in the world. It is caused by the oncogenic human papilloma virus (HPV). The inhibition activity of histone deacetylase (HDAC) is a potential strategy for cancer therapy. Suberoylanilide hydroxamic acid (SAHA) is widely known as a low toxicity HDAC inhibitor. This research presents in silico SAHA modification by utilizing triazole, in order to obtain a better inhibitor. We conducted docking of the SAHA inhibitor and 12 modified versions to six class II HDAC enzymes, and then proceeded with drug scanning of each one of them.

Results: The docking results show that the 12 modified inhibitors have much better binding affinity and inhibition potential than SAHA. Based on drug scan analysis, six of the modified inhibitors have robust pharmacological attributes, as revealed by drug likeness, drug score, oral bioavailability, and toxicity levels.

Conclusions: The binding affinity, free energy and drug scan screening of the best inhibitors have shown that $1 \mathrm{c}$ and 2c modified inhibitors are the best ones to inhibit class II HDAC.
\end{abstract}

\section{Background}

Cervical cancer is one of the most prevalent cancers for women, and it is the most prevalent one in developing countries. It is estimated that in the year 2000 , there were 470,600 new cervical cancer cases, with 233,400 deaths. Moreover, 80 \% of these cases happened in developing countries [1]. In Indonesia, it is estimated, that there are 100 new cervical cancer cases per 100,000 people. It is known that $70 \%$ of them are in the late stages [2].

Cervical cancer occurs at the area known as the cervix. The cause of this cancer is the human papilloma virus (HPV), a member of the Papillomaviridae family. More than 120 types of HPV have been identified, and out of that number, 15 of them are classified as high risk HPV types $(16,18,31,33,35,39,45,51,52,56,58,59,68,73$,

\footnotetext{
* Correspondence: usman@ui.ac.id

Department of Chemistry, Faculty of Mathematics and Science, University of Indonesia, Depok, Indonesia
}

and 82$)$ with 12 of them being low risk HPV types $(6,11$, 40, 42, 43, 44, 54, 61, 70, 72, 81, and CP6108). Types 16 and 18 are the main cause of the $70 \%$ of cervical cancer case, while $41-54 \%$ caused by Type 16 HPV alone [3]. The most effective and safe method for tackling HPV infection is still not available, with treatments options being surgery and/or with physico or chemotherapy [4].

The inhibition of histone deacetylase (HDAC) activity, which is manifested by the destruction of HDAC complex, has been widely known as a potent measure to combat cervical cancer. HDAC (EC 3.5.1) is the enzyme, which catalyzes the histone deacetylation within eukaryotes. Deacetylation is a release of the acetyl group from the histone tail, and it causes the histone to be twisted around the DNA, disrupting gene transcription, by blocking the pathway of transcription factor binding [5]. The inhibition of HDAC by its specific inhibitor shows a couple of changes at the molecular and cellular level [6]. The HDAC activity

\section{Ciomed Central}

(c) 2011 Tambunan et al; licensee BioMed Central Ltd. This is an open access article distributed under the terms of the Creative Commons Attribution License (http://creativecommons.org/licenses/by/2.0), which permits unrestricted use, distribution, and reproduction in any medium, provided the original work is properly cited. 
inhibition by specific inhibitors could induce the death of the cancer cell [5].

Vorinostat or suberoylanilide hydroxamic acid (SAHA) is the most widely used inhibitor of class II HDAC activity. This inhibitor has carbonyl and hydroxylamine groups, which will bind to the zinc ion, $\mathrm{Zn}^{2+}$, with the aliphatic chain as linker, and the hydrophobic group in the other tail. Our research group has successfully determined the efficacy of SAHA as a potential class II HDAC inhibitor [4].

We are looking to compare the efficacy of SAHA with other types of inhibitors, by searching for the new ones or modifications of the existing ones. Triazole is known as a non-classical amide bioisostere compound [7]. Triazole could replace the amide bond in the SAHA side group without losing its activity significantly [8].

We are interested to modify the SAHA compound, by creating new ones. The processes we have followed are replacing one of the amides group within the SAHA hydrophobic group with triazole, and adding triazole as hydrophobic group toward SAHA. Then, we conduct molecular docking with Class II HDAC, and testing its toxicity, and finally compare the result with standard SAHA inhibitor. This structure-activity relationship (SAR) study is very important in uncovering novel inhibitors of HDAC.

\section{Material and methods}

Collecting the Homo sapiens Class II HDAC sequences and its 3D structure

Collecting of Homo sapiens Class II HDAC sequences was done by downloading them from the protein database at NCBI site (http://www.ncbi.nlm.nih.gov). The Homo sapiens Class II HDAC 3D crystal structure was downloaded from the PDB structural database site (http://www.rcsb.org/pdb). The sequences were analyzed to determine whether there are any newly curated sequences or not.

\section{Sequence conservation at the Homo sapiens class II HDAC catalytic site}

ClustalW multiple sequence alignment of the collected Homo sapiens Class II HDAC sequences was carried out. The alignment results were analyzed with BioEdit, in order to obtain the existing catalytic site. The conserved region information was the result of the Homo sapiens Class II HDAC sequence alignment with its 3D structure sequences. The sequence for modelling will be the one that is closely resembles the crystal structure of Homo sapiens Class II HDAC. This research follows on from the previous research, which used Class II HDAC Homo sapiens [4]. If the result of the sequence alignment is the same with the previous ones, the Class II HDAC Homo sapiens structure will be generated from it, without the necessity of conducting another homology modelling process.

\section{Design of SAHA and modified SAHA inhibitors}

This is the beginning of SAR study. The structure of SAHA and modified SAHA were designed by using ChemSketch 12.0 software. Various SAHA modifications were utilized. The output of ChemSketch 12.0 is in the $\mathrm{mol}$ format. It functions as an input for docking simulations with class II HDAC of Homo sapiens, and to test the pharmacology and toxicity attributes. The ligands were saved in MDL Molfile format. Then, they were converted to pdb format by using OpenBabel 2.2.3 or Vegazz software.

\section{Preparation of class II HDAC Homo sapiens docking}

Class II HDAC Homo sapiens structure files were prepared in pdb format. Then, its variations: HDAC 4, 5, 6, 7, 9, and 10 were loaded with AutoDock Tools, and polar hydrogen was added to each of those HDAC. The addition is useful for giving the partial charges/gasteiger charges to those enzymes. Then, they were saved in pdbqt format. Then, the $\mathrm{Zn}$ charge of class II HDAC Homo sapiens was converted from 0 to +2 by using python script. Then, the molecule was adjusted as macromolecule for the docking process.

Preparation of class II HDAC Homo sapiens inhibitor file The inhibitors or ligands in pdb format were loaded with AutoDock Tools software. Then, the torsion of the ligand was adjusted based on the total number of rotatable bonds. Ligands were saved in pdbqt format.

\section{Grid box preparation}

The preparation steps were started by using pdb file of Homo sapiens Class II HDAC as the receptor, and SAHA with its various ligand modifications. Grid Box is the coordinate area determination for the docking process. It is configured in AutoDock Tools. The grid box size for the docking of HDAC 4, HDAC 5, HDAC 6, HDAC 7, HDAC 9, and HDAC 10 with the ligands are consecutively $19.228,-6.296,0.177 ; 19.696,-6.093,0.513 ; 15.326$, $-7.608,8.495 ; 18.484,-6.198,-0.744 ; 18.078,-7.314$, -2.129 and $17.713,-6.707,1.288$, with the spacing between grid points of $0.375 \AA$. We obtained those numbers from our previous research [4]. The best docking model result was then picked. The grid box was saved in a grid parameter file (gpf) format.

\section{Docking simulation}

This process was done using AutoGrid 4.2 and AutoDock 4.2. The following data are necessary for conducting the docking: enzyme file in pdbqt format, ligand in pdbqt format, gpf files, dpf files. The utilized algorithm is 
Lamarckian Genetic Algorithm (LGA) with the population size of 150, energy evaluation of $2.5 \times 10^{6}$ and search runs of 100 times within the RMSD of 1.5.

\begin{abstract}
Analysis and visualization of docking simulation results The docking result of AutoDock 4.2 is in the docking log file (dlg) format. Then, by using python script, the docking results were converted to pdb format. Out of 100model result, one best model was picked up, based on the free energy bonding data, in order to analyze its interaction.
\end{abstract}

\section{Drug scan}

This was conducted in order to determine, whether the inhibitor has fulfilled the conditions as the drug candidate based on Lipinski's Rule of Five. It is done using Lipinski Filters, Molinspiration, Osiris Property Explorer, Toxtree v2.1.0 and Lazar software.

Molinspiration and Lipinski Filters were utilized for analyzing the molecular attributes, such as $\log \mathrm{P}$, the amount of hydrogen bond donors, the amount of hydrogen bond acceptor, and the molecular mass of the drugs. Moreover, the Osiris Property Explorer, Toxtree v2.1.0, and Lazar calculated various attributes of the drugs, such as toxicity, drug likeness, and drug score.

In order to use Lipinski Filters, the ligand in pdb format must be uploaded to the analysis software website. The same applies to Molinspiration, Lazar, and Toxtree v2.1.0, because the ligand in smiles format must be uploaded to their websites. However, to use Osiris Property Explorer, the ligand could be drawn offline.

\section{Results and discussion}

\section{Determination of class II HDAC Homo sapiens}

The results of the class II HDAC Homo sapiens search in the NCBI sites are 65 sequences shown in Table 1.

Those sequences were downloaded in FASTA format, in order to conduct multiple sequences alignment for each class II HDAC Homo sapiens. The ones with the highest score are chosen as the modelling sequences. The alignment results were compared with the class II HDAC Homo sapience sequence from previous research [4]. The obtained sequences for HDAC 4, HDAC 5, HDAC 6, HDAC 7, HDAC 9, and HDAC 10 are [Genbank:NP_006028.2, Genbank:NP_005465.2, Genbank:NP_006035.2, Genbank:NP_056216.2, Genbank: NP_848510.1, and Genbank:NP_114408.3] consecutively. These sequences are the same as the sequences from our previous research [4]. Henceforth, this research utilized the 3D structure of class II HDAC Homo sapiens without the need to redo the homology modelling. Class II HDAC Homo sapiens has a long chain length (over than 1000 amino acid). In that case, the modelling was conducted by extracting the conserved region. The 3D structure of class II HDAC Homo sapiens are the catalytic area based on its conserved region [4], shown in Figure 1.

The visualization of the class II HDAC Homo sapiens active site

The 3D structure of class II HDAC Homo sapiens modelling results are saved in pdb format. PyMol visualization (Figure 2) shows, that the enzyme has cofactor $\mathrm{Zn}^{2+}$ as catalytic site, which is bound to three amino acid residues. These are two aspartic acids and one histidine residue.

The position of the catalytic sites of each class II HDAC is different. Table 2 shows the positions of the catalytic sites of HDAC4, HDAC 5, HDAC 6, HDAC7, HDAC9, and HDAC 10.

\section{The Design of class II HDAC Homo sapiens inhibitors}

12 modified ligands and one standard ligand were drawn by using ACDLabs ChemSketch 12.0. Those 12 modified ligands could be classified as two groups. The first one utilises triazole as substituent of the amide group at SAHA (Figure 3). The second one utilises triazole as additional group of SAHA, without substituting the amide group (Figure 4). Both modifications are made in their alkyl groups (R groups) (Figure 5).

The triazole bioisostere attributes on SAHA amide group could eventually modify SAHA's properties. The hydrophobic tendency of triazole compared with the amide group on SAHA was expected to increase the binding affinity of modified ligands toward class II HDAC Homo sapiens. Thus, the binding of enzyme-ligand complex would be much stronger [8]. Triazole could be treated as an additional functional group on SAHA, which could increase the hydrophobic attributes of SAHA cap group [9].

The six alkyl groups for modified ligand variations are phenyl $\left(\mathrm{C}_{6} \mathrm{H}_{5}\right)$, phenylamine $\left(\mathrm{C}_{6} \mathrm{H}_{4} \mathrm{NH}_{2}\right)$, cyclohexyl $\left(\mathrm{C}_{6} \mathrm{H}_{11}\right)$, fluorophenyl $\left(\mathrm{C}_{6} \mathrm{H}_{4} \mathrm{~F}\right)$, hydroxyphenyl $\left(\mathrm{C}_{6} \mathrm{H}_{4} \mathrm{OH}\right)$, and iodophenyl $\left(\mathrm{C}_{6} \mathrm{H}_{4} \mathrm{I}\right)$. The selections of those alkyl groups are based on hydrophobic attributes of those groups. Thus, this study would observe the influence of the cap group hydrophobicity of each modified ligand, in comparison with the SAHA standard ligand.

The design of the standard ligand and its modifications are conducted by clean structure procedure and 3D optimization with ChemSketsch 12.0. The objective of this treatment is to smooth the designed ligand structure, while the $3 \mathrm{D}$ optimization was conducted to visualize the ligand when the docking process is running.

\section{Preparation of the enzyme and ligand files for docking}

The prepared files for the docking process are enzyme and ligand in pdbqt format, grid box parameter in gpf 
Table 1 Class II HDAC Homo sapiens sequence search result.

\begin{tabular}{|c|c|c|}
\hline Enzyme & $\begin{array}{c}\text { Sequence } \\
\text { amount }\end{array}$ & Sequence code \\
\hline HDAC 4 & 5 & [Genbank: NP_006028.2, Genbank:AAD29046.1, Genbank:EAW71166.1, Genbank:EAW71165.1, Genbank:P56524.3] \\
\hline HDAC 5 & 7 & [Genbank: AAD29047.1, Genbank: Q9UQL6.2, Genbank: AAH51824.1, Genbank: NP_001015053.1, Genbank: NP_005465.2; EAW51634.1, Genbank: EAW51633.1] \\
\hline HDAC 6 & 9 & $\begin{array}{c}\text { \{Genbank:NP_006035.2, Genbank: AAD29048.1, Genbank: AAP35295.1, Genbank: Q9UBN7.2, Genbank: EAW50748.1, Genbank: EAW50747.1, Genbank: EAW50746.1, Genbank: } \\
\text { EAW50745.1, Genbank: EAW50744.1\} }\end{array}$ \\
\hline HDAC 7 & 4 & [Genbank:AAF63491.1, Genbank: Q8WUI4.2, Genbank: NP_056216.2, Genbank: NP_001091886.1] \\
\hline HDAC 9 & 20 & $\begin{array}{r}\text { [Genbank:AA152406.1, Genbank: AAl50329.1, Genbank: AAl11736.1, Genbank: NP_848512.1, Genbank: NP_848510.1, Genbank: NP_478056.1, Genbank: NP_055522.1, } \\
\text { Genbank: AAO27363.1, Genbank: AAK66821.1, Genbank: Q9UKV0.2, Genbank: EAW93706.1, Genbank: EAW93705.1, Genbank: EAW93704.1, Genbank: EAW93710.1, Genbank: } \\
\text { EAW93709.1, Genbank: EAW93708.1, Genbank: EAW93707.1, Genbank: EAW93703.1, Genbank: EAW93702.1, Genbank: EAW93701.1] }\end{array}$ \\
\hline $\begin{array}{l}\text { HDAC } \\
10\end{array}$ & 20 & $\begin{array}{l}\text { [Genbank:AAL30513.1, Genbank: AAl25084.1, Genbank: AAS48345.1, Genbank: Q96958.10, Genbank: NP_001152758.1, Genbank: NP_114408.3, Genbank: AAK92206.1, } \\
\text { Genbank: AAK92205.1, Genbank: AAK84023.1, Genbank: EAW73519.1, Genbank: EAW73518.1, Genbank: EAW73515.1, Genbank: EAW73514.1, Genbank: EAW73513.1, } \\
\text { Genbank: EAW73512.1, Genbank: EAW73511.1, Genbank: EAW73520.1, Genbank: EAW73517.1, Genbank: EAW73516.1, Genbank: BAD92656.1] }\end{array}$ \\
\hline
\end{tabular}




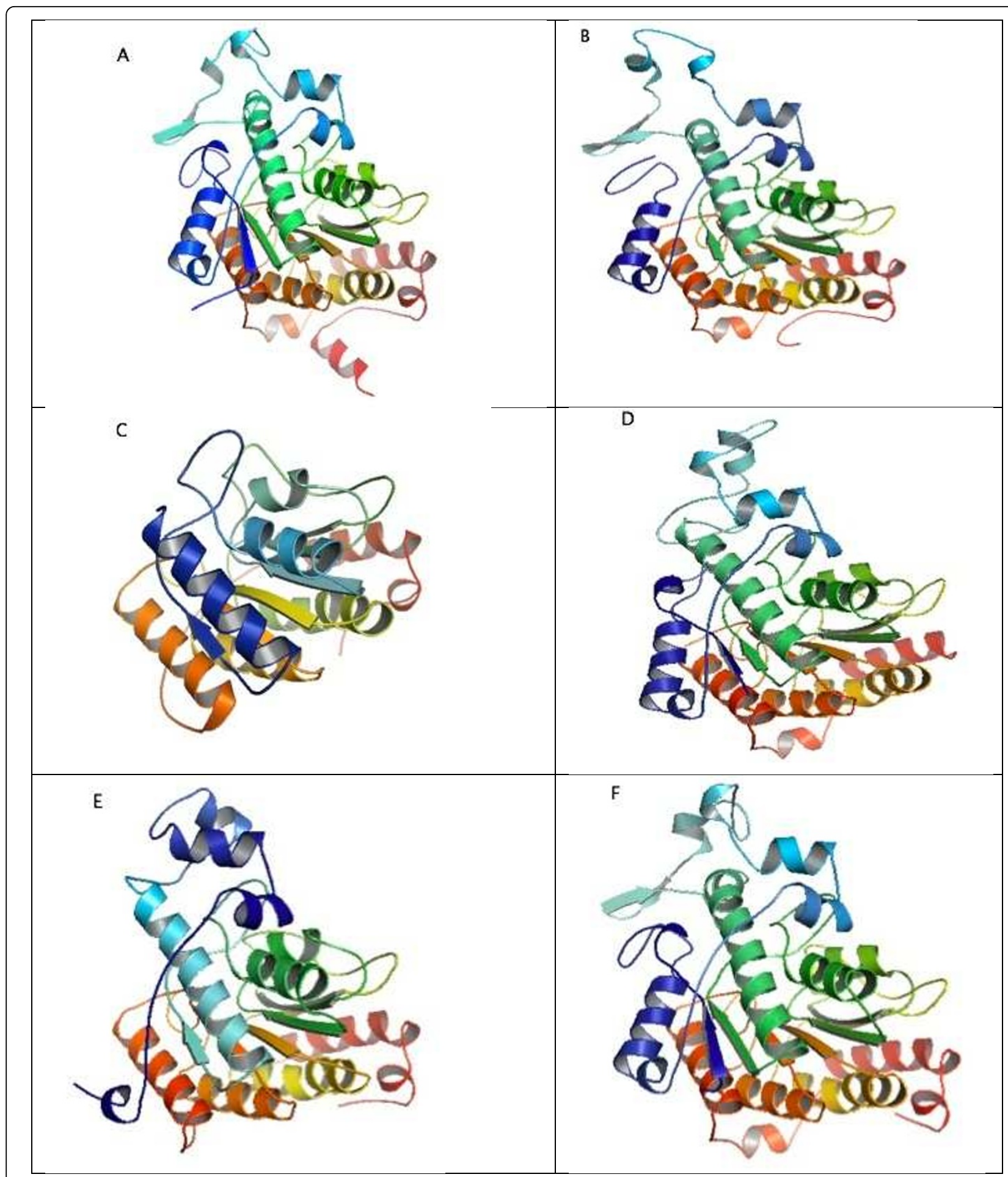

Figure 1 Catalytic regions of the crystal structure of HDAC enzymes. A. HDAC 4 Homo sapiens. B. HDAC 5 Homo sapiens. C. HDAC 6 Homo sapiens. D. HDAC 7 Homo sapiens. E. HDAC 9 Homo sapiens. F. HDAC 10 Homo sapiens. The catalytic regions of the 3D structure of class II HDAC Homo sapiens shown are based on their conserved regions.

format, and docking parameter in dpf format. Pdbqt Format of enzyme and ligand show that both of them have undergone partial charge changes and atom type rearrangement. Zn with zero charge would not be recognized as a cofactor by the enzyme. Thus, $\mathrm{Zn}$ metal on class II HDAC Homo sapiens must undergo charge 


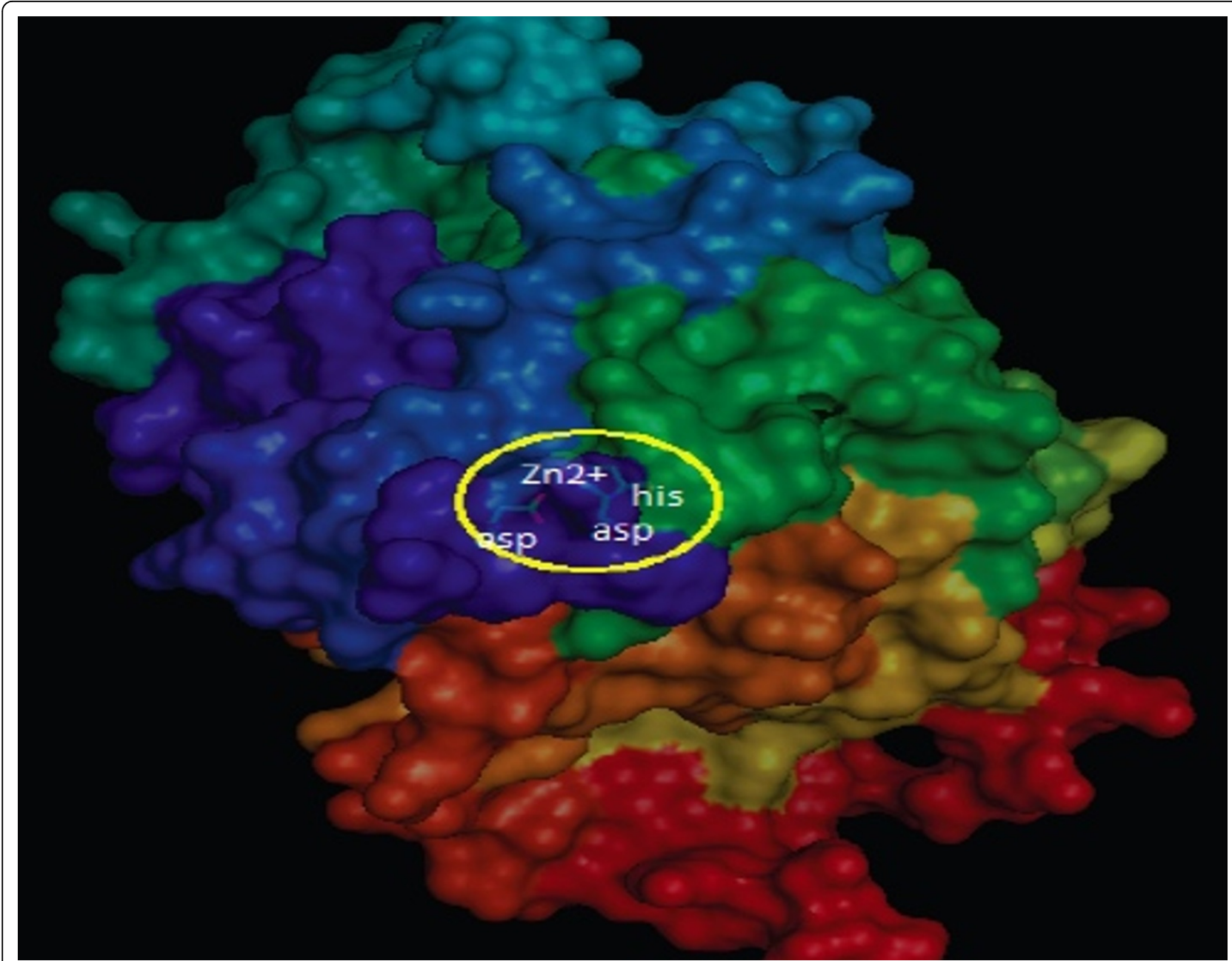

Figure 2 The visualization of class II HDAC Homo sapiens active site. PyMol visualization shows, that the utilized enzyme has cofactor $\mathrm{Zn}^{2+}$ as catalytic site, which is bound to three amino acid (two aspartic acid and one histidine) residues.

change to $\mathrm{Zn}^{2+}$ ion. This would be necessary for the ligand to interact with $\mathrm{Zn}^{2+}$ cofactor during the docking process.

When the ligands have been loaded with AutoDockTools, the amount of rotatable bonds were verified. The rotatable bonds are necessary to arrange the ligand torsional degree for docking process. If the amount of rotatable bonds and ligand torsional degree are increased,

\section{Table 2 Location of class II HDAC Homo sapiens catalytic} sites.

\begin{tabular}{ll}
\hline Enzyme & Location of catalytic site \\
\hline HDAC 4 & lon $\mathrm{Zn}^{2+}$ dengan residu Asp193, His195, and Asp287 \\
HDAC 5 & lon $\mathrm{Zn}^{2+}$ dengan residu Asp178, His180, and Asp272 \\
HDAC 6 & lon $\mathrm{Zn}^{2+}$ dengan residu Asp71, His73, and Asp164 \\
HDAC 7 & lon $\mathrm{Zn}^{2+}$ dengan residu Asp191, His193, and Asp285 \\
HDAC 9 & lon $\mathrm{Zn}^{2+}$ dengan residu Asp188, His190, and Asp282 \\
HDAC 10 & Ion $\mathrm{Zn}^{2+}$ dengan residu Asp133, His135, and Asp226 \\
\hline
\end{tabular}

then the ligands would be more flexible, causing more variation in the docking process.

The grid box parameters are necessary to describe the docking process area. The docking parameters are needed to give necessary conditions in the docking process, and include the flexibility of enzyme, the selection of ligand, and the selection of the utilized algorithm.

\section{Docking}

This process is of two types: blind and oriented docking. Blind docking is a docking process without knowing the position of the enzyme's active site, and then during the grid box determination, the utilized grid center is not specific to the certain area, but applied to the whole enzyme area. Oriented docking was done by determine the position of the enzyme active site, and then the grid box could be specifically resolved. This research used oriented docking, because the active site region has been determined. 


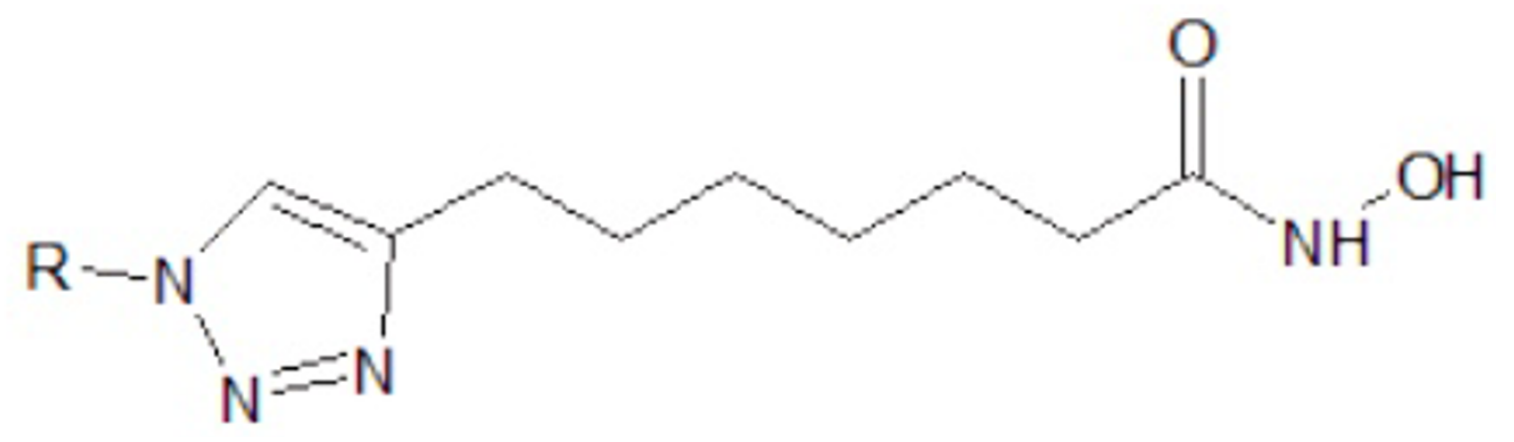

Figure 3 The first modification of SAHA ligand. This utilises triazole as substituent of amide group at SAHA.

This docking process is semi-flexible, which means that the ligand was made flexible, while the enzyme was rigid. The docking was started by utilize autogrid with Autogrid 4.2 software. The objective is to map the area for docking process. The autogrid process was done using the determined grid box. The dimension of the utilized grid box must be big enough, in order that the ligand can be freely rotated [10]. The autogrid result in grid log file (glg) format would be applied as parameters for docking process.

This docking process used the Lamarckian Genetic Algorithm (LGA). This algorithm is recommended, because it is a hybridization of Local Search and Genetic Algorithm. The energy evaluation values and utilized search runs would have impacts on docking duration and docking energy values. The amounts of search runs are the total iteration or docking replication [10]. This study has conducted 100 iterations, and it would result in 100 inhibitor models on each docking.

\section{Interaction of the inhibitor with class II HDAC Homo sapiens}

The docking results with AutoDock 4.2 were saved in dlg format. However, visualizing them in $3 \mathrm{D}$ graphic requires conversion to pdb format. The docking results in $\mathrm{pdb}$ can be visualized by PyMol software. One out of 100 models was taken as the best ligand mode, based on the best binding energy interaction between standard polar group ligand, and $\mathrm{Zn}^{2+}$ cofactor modification as enzyme catalytic site. The chosen interaction is the ligand model which has $\mathrm{Zn}^{2+}$ cofactor binding $\mathrm{O}$ atom on the $\mathrm{C}=\mathrm{O}$ and $-\mathrm{OH}$ groups.

The docking result in this study shows, that the standard SAHA ligand and both modified ligands have equal amount of interaction toward $\mathrm{Zn}^{2+}$ cofactor. It is electrostatic attraction of both $\mathrm{O}$ atom on $\mathrm{C}=\mathrm{O}$ and $-\mathrm{OH}$ functional groups toward $\mathrm{Zn}^{2+}$ cofactor. Moreover, the SAHA standard ligand and both modified ligands have hydrogen bonds with amino acid residues nearby the $\mathrm{Zn}^{2+}$ ion. This case made the binding interaction not applicable for determining which ligand has the best affinity toward $\mathrm{Zn}^{2+}$. The interaction of SAHA standard ligand and both modified ligands toward class II HDAC Homo sapiens are presented in Tables 3 and 4 .

Binding free energy $\left(\Delta \mathrm{G}_{\text {binding }}\right)$ and inhibition constant $\left(K_{i}\right)$ The results of the docking are the $\Delta \mathbf{G}_{\text {binding }}$ and $K_{i}$ values. The selection of AutoDock 4.2 best model ligand calculation result was based on the lowest binding free energy, and ligand interaction toward $\mathrm{Zn}^{2+}$ ion at the enzyme. The selection is not based on the cluster result. The values of the binding free energy and inhibition<smiles>[R]n1cc(-c2cccc(NC(=O)CCCCCCC(=O)NO)c2)nn1</smiles>

Figure 4 The second modification of SAHA ligand. This utilises triazole as additional group of SAHA, without substituting the amide group. 




Figure 5 The modified alkyl group. Both modifications in figures 3 and 4 are made in their alkyl (R) groups.

constant are available from Tables 5 and 6 . The docking result shows, that all 12 modified ligands have lower binding free energy and inhibition constant values, compared with the SAHA standard ligand, for every enzyme in class II HDAC Homo sapiens. Ligand 2c has the smallest binding free energy and inhibition constant in HDAC 4 and HDAC 6 . Ligand $2 \mathrm{f}$ has the smallest values for HDAC 5. Ligands $2 \mathrm{~d}$ and $2 \mathrm{f}$ have the smallest values for HDAC 7. Last but not least, ligand 1c has the smallest values for HDAC 9 and HDAC 10.

The AutoDock values of $\boldsymbol{\Delta} \mathbf{G}_{\text {binding }}$ in Table 5 show that every ligand has negative $\Delta \mathbf{G}$. It shows that the SAHA standard and modified ligand conformation complex with the tested HDAC, are much more stable than the individual conformations. It happens because binding releases energy, which is useful for decreasing the activation energy of catalytic reaction [4]. The negative binding free energy shows that the reaction is spontaneous. Tables 5 and 6 showed that the binding free energy values of each ligand are related to its inhibition constant values. The best ligand for each class II HDAC Homo sapiens has the smallest $\Delta \mathbf{G}_{\text {binding }}$ and $K_{i}$.

\section{Pharmacology inhibition prediction}

Molinspiration, Lipinski Filters, and Osiris Property Explorer were utilized to screen the drug candidate

Table 3 Interaction of SAHA standard ligand and first modified ligand with class II HDAC Homo sapiens.

\begin{tabular}{|c|c|c|c|c|c|c|}
\hline \multirow[t]{2}{*}{ Ligand } & \multicolumn{6}{|c|}{ Docking interaction } \\
\hline & HDAC 4 & HDAC 5 & HDAC 6 & HDAC 7 & HDAC 9 & HDAC 10 \\
\hline SAHA & $\begin{array}{l}\mathrm{Zn}^{2+}, \text { Asp287, } \\
\text { His155, His 195 }\end{array}$ & $\begin{array}{c}\mathrm{Zn}^{2+}, \text { Asp272, } \\
\text { His } 140\end{array}$ & 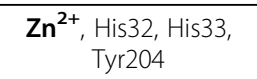 & $\begin{array}{c}\mathrm{Zn}^{2+}, \text { Asp191, His153, } \\
\text { His154 }\end{array}$ &  & $\begin{array}{l}\text { Zn }^{2+}, \text { Asp226, His95, } \\
\text { His96, Phe163, Tyr266 }\end{array}$ \\
\hline $1 \mathrm{a}$ & $\begin{array}{l}\mathrm{Zn}^{2+}, \text { Asp287, } \\
\text { His155, Pro295 }\end{array}$ & $\begin{array}{l}\mathrm{Zn}^{2+}, \text { Asp178, } \\
\text { His140, His180 }\end{array}$ & 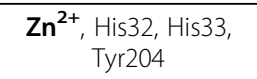 & $\begin{array}{c}\mathrm{Zn}^{2+}, \text { Asp191, Glu115, } \\
\text { His153 }\end{array}$ & $\begin{array}{c}\mathrm{Zn}^{2+}, \text { Asp282, His150, } \\
\text { His151 }\end{array}$ & $\begin{array}{c}\mathrm{Zn}^{2+}, \text { Asp133, His95, } \\
\text { His96, Tyr266 }\end{array}$ \\
\hline $1 b$ & $\begin{array}{l}\mathbf{Z n}^{2+}, \text { Asp193, } \\
\text { His155, Pro295 }\end{array}$ & $\begin{array}{l}\mathbf{Z n}^{2+}, \text { Asp178, } \\
\text { His140, His141, } \\
\text { Pro280 }\end{array}$ & $\begin{array}{c}\mathbf{Z n}^{2+}, \text { Asp164, His32, } \\
\text { His33, Tyr204 }\end{array}$ & $\begin{array}{c}\text { Zn }^{2+}, \text { Ala160, Asp191, } \\
\text { Glu115, His153, His154, } \\
\text { Thr109 }\end{array}$ & $\begin{array}{c}\mathbf{Z n}^{\mathbf{2 +}}, \text { Asp105, Asp107, } \\
\text { Asp188, His150, } \\
\text { His151 }\end{array}$ & $\begin{array}{c}\mathbf{Z n}^{\mathbf{2 +}}, \text { Asn103, } \\
\text { Asp133, His95, His96 }\end{array}$ \\
\hline $1 c$ & $\begin{array}{l}\mathbf{Z n}^{2+}, \text { Asp193, } \\
\text { His155, Leu296 }\end{array}$ & $\begin{array}{c}\mathrm{Zn}^{2+}, \text { Asp178, } \\
\text { His140 }\end{array}$ & $\begin{array}{c}\mathbf{Z n}^{\mathbf{2 +}}, \text { His32, His33, } \\
\text { Thr100, Tyr204 }\end{array}$ & $\begin{array}{l}\text { Zn }^{2+}, \text { Asp191, Glu115, } \\
\text { His153, His154, Thr109 }\end{array}$ & $\begin{array}{c}\mathrm{Zn}^{2+}, \text { Asp188, } \\
\text { Asp282, His150, } \\
\text { His151 }\end{array}$ & $\begin{array}{c}\mathbf{Z n}^{2+}, \text { Asp133, His95, } \\
\text { His96, Tyr226 }\end{array}$ \\
\hline $1 d$ & $\begin{array}{c}\mathrm{Zn}^{2+}, \text { Asp287, } \\
\text { His155 }\end{array}$ & $\begin{array}{l}\mathrm{Zn}^{2+}, \text { Asp178, } \\
\text { His140, Glu102 }\end{array}$ & $\begin{array}{c}\mathrm{Zn}^{2+}, \text { His32, Thr100, } \\
\text { Tyr204 }\end{array}$ & $\begin{array}{c}\mathbf{Z n}^{2+}, \text { Asp285, Glu115, } \\
\text { His154, Thr109 }\end{array}$ & $\begin{array}{c}\mathbf{Z n}^{\mathbf{2 +}}, \text { Asp188, His150, } \\
\text { His151, Pro290 }\end{array}$ & $\begin{array}{c}\mathrm{Zn}^{2+}, \text { Asp133, His95, } \\
\text { His96 }\end{array}$ \\
\hline $1 e$ & $\begin{array}{l}\mathbf{Z n}^{2+}, \text { Asp193, } \\
\text { His155, Pro295 }\end{array}$ & $\begin{array}{l}\mathrm{Zn}^{2+}, \text { Glu102, } \\
\text { Gly149, His140 }\end{array}$ & $\begin{array}{l}\mathbf{Z n}^{2+}, \text { Asp164, His32, } \\
\text { His33, Pro103, Tyr204 }\end{array}$ & $\begin{array}{c}\text { Zn }^{2+}, \text { Ala160, Asp191, } \\
\text { Glu115, His153, Thr109, } \\
\text { Thr111 }\end{array}$ & $\begin{array}{c}\mathbf{Z n}^{2+}, \text { Asp105, His150, } \\
\text { His151 }\end{array}$ & $\begin{array}{c}\mathrm{Zn}^{2+}, \text { His95, His96, } \\
\text { Asp133 }\end{array}$ \\
\hline if & $\begin{array}{l}\mathbf{Z n}^{2+}, \text { Asp287, } \\
\text { Gly328, His155, } \\
\text { Pro295 }\end{array}$ & $\begin{array}{l}\mathbf{Z n}^{2+}, \text { Asp178, } \\
\text { Gu102, His140 }\end{array}$ & $\begin{array}{l}\mathbf{Z n}^{2+}, \text { Asp164, His32, } \\
\text { His33, Thr100, Tyr204 }\end{array}$ & $\begin{array}{c}\mathrm{Zn}^{2+}, \text { Asp110, Asp191, } \\
\text { His153, His154, Thr109, } \\
\text { Thr111 }\end{array}$ & $\mathrm{Zn}^{2+}$, Asp188, His150 & $\begin{array}{c}\mathbf{Z n}^{2+}, \text { Asp133, His95, } \\
\text { His96 }\end{array}$ \\
\hline
\end{tabular}

* Bold is the catalytic sites. 
Table 4 Interaction of SAHA standard ligand and second modified ligand with class II HDAC Homo sapiens

\begin{tabular}{|c|c|c|c|c|c|c|}
\hline \multirow[t]{2}{*}{ Ligand } & \multicolumn{6}{|c|}{ Docking interaction } \\
\hline & HDAC 4 & HDAC 5 & HDAC 6 & HDAC 7 & HDAC 9 & HDAC 10 \\
\hline SAHA & $\begin{array}{l}\mathbf{Z n}^{\mathbf{2 +}}, \mathbf{A s p 2 8 7} \\
\text { His155, His } 195\end{array}$ & $\begin{array}{c}\mathrm{Zn}^{2+}, \text { Asp272 } \\
\text { His } 140\end{array}$ & $\begin{array}{c}\mathbf{Z n}^{2+}, \text { His32, His33, } \\
\text { Tyr204 }\end{array}$ & $\begin{array}{c}\mathbf{Z n}^{2+}, \text { Asp191, His153, } \\
\text { His154 }\end{array}$ & $\begin{array}{c}\mathbf{Z n}^{\mathbf{2 +}}, \mathbf{A s p 1 8 8 , H i s 2 2} \\
\text { His150, His151 }\end{array}$ & $\begin{array}{c}\mathbf{Z n}^{\mathbf{2 +}}, \text { Asp226, } \\
\text { His95, His96, Phe163, } \\
\text { Tyr266 }\end{array}$ \\
\hline $2 b$ & $\begin{array}{l}\mathrm{Zn}^{2+}, \text { Asp193, } \\
\text { Glu117, His155, } \\
\text { Pro162, Tyr167 }\end{array}$ & $\mathrm{Zn}^{2+}, \mathrm{His} 140$ & $\begin{array}{l}\text { Zn }^{2+}, \text { Ala39, } \\
\text { Asp71, His32, } \\
\text { His33, Gly202 }\end{array}$ & $\begin{array}{c}\mathbf{Z n}^{2+}, \text { Ala160, Glu115, } \\
\text { His153, Phe163, Thr109, } \\
\text { Thr111 }\end{array}$ & 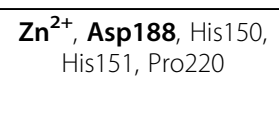 & $\begin{array}{l}\mathbf{Z n}^{2+}, \text { Asn103, } \\
\text { Asp133, His95, } \\
\text { Phe163 }\end{array}$ \\
\hline $2 c$ & $\mathrm{Zn}^{2+}$, Asp193, His155 & $\begin{array}{c}\mathrm{Zn}^{2+}, \text { Asp178, } \\
\text { His } 140\end{array}$ & $\begin{array}{c}\mathbf{Z n}^{2+}, \text { His32, His33, } \\
\text { Tyr204 }\end{array}$ & $\begin{array}{l}\mathrm{Zn}^{2+}, \text { Asp191, Glu115, } \\
\text { His153, Thr109, Thr111 }\end{array}$ & $\begin{array}{c}\mathbf{Z n}^{2+}, \text { Asp188, Gly322, } \\
\text { His150, His151 }\end{array}$ & $\begin{array}{c}\mathbf{Z n}^{2+}, \text { Asp133, } \\
\text { His95, His96, Phe163 }\end{array}$ \\
\hline $2 d$ & $\begin{array}{l}\mathrm{Zn}^{2+}, \text { Asp193, } \\
\text { His155, Tyr167 }\end{array}$ & $\begin{array}{c}\mathbf{Z n}^{\mathbf{2 +}}, \mathbf{A s p 1 7 8} \\
\text { His140, His141, } \\
\text { Glu102 }\end{array}$ & $\begin{array}{c}\mathbf{Z n}^{2+}, \text { His32, His33, } \\
\text { Tyr204 }\end{array}$ & $\begin{array}{l}\mathbf{Z n}^{2+}, \text { His153, His154, } \\
\text { Phe163 }\end{array}$ & $\begin{array}{c}\mathrm{Zn}^{2+}, \text { Asn217, Asp188, } \\
\text { His190 }\end{array}$ & $\begin{array}{c}\mathbf{Z n}^{\mathbf{2 +}}, \text { Asn103, } \\
\text { Asp133, His95, } \\
\text { His96, Tyr266 }\end{array}$ \\
\hline $2 e$ & $\mathrm{Zn}^{2+}$, Asp193, His155 & $\begin{array}{c}\mathbf{Z n}^{2+}, \text { Asp178, } \\
\text { His140, Tyr60 }\end{array}$ & $\begin{array}{c}\mathbf{Z n}^{2+}, \text { Gly99, His32, } \\
\text { His33, Tyr204 }\end{array}$ & $\begin{array}{c}\mathbf{Z n}^{2+}, \text { Asp285, Glu115 } \\
\text { Gly326 }\end{array}$ & $\begin{array}{c}\mathbf{Z n}^{2+}, \text { Asp188, His150, } \\
\text { His151, His190, Ser19, } \\
\text { Thr20 }\end{array}$ & $\begin{array}{c}\mathbf{Z n}^{2+}, \text { Asp133, } \\
\text { Gln98, His96, Phe163 }\end{array}$ \\
\hline $2 f$ & $\begin{array}{l}\mathrm{Zn}^{2+}, \text { Asp193, } \\
\text { His155, His195 }\end{array}$ & $\begin{array}{l}\mathbf{Z n}^{2+}, \text { Asp178, } \\
\text { His140, Phe209 }\end{array}$ & $\mathrm{Zn}^{2+}$, His32, Thr100 & $\begin{array}{c}\mathbf{Z n}^{2+}, \text { Asp110, Asp285 } \\
\text { His153, His154 }\end{array}$ & $\begin{array}{l}\mathbf{Z n}^{2+}, \text { Asp188, Asp217, } \\
\text { Gly322, His150, His151 }\end{array}$ & $\begin{array}{c}\mathrm{Zn}^{2+}, \text { Asn103, } \\
\text { Asp133, His95, } \\
\text { His96, }\end{array}$ \\
\hline
\end{tabular}

* Bold is the catalytic sites..

based on Lipinski's Rule of Five and Oral Bioavailability. The prediction results of the pharmacological attributes are in Table 7.

The parameters of Lipinski's Rule of Five are as follows: the molecular weight must be less than $500 \mathrm{Da}$, LogP less than 5, the amount of Hydrogen donor (n OHNH) must be less than 5 , the amount of acceptor hydrogen (n ON) must be less than 10, and the refractivity molar range must be between 40-130. The last parameter is optional, because in the previous research, the emphasized parameters are the first four. However, the drug scan result

Table 5 The binding free energy docking simulation result of SAHA standard ligand and its modification toward class II HDAC Homo sapiens

\begin{tabular}{ccccccc}
\hline Ligand & \multicolumn{6}{c}{ Binding energy, $\Delta \mathbf{G}(\mathbf{k c a l} / \mathbf{m o l})$} \\
\cline { 2 - 7 } & HDAC 4 & HDAC 5 & HDAC 6 & HDAC 7 & HDAC 9 & HDAC 10 \\
\hline SAHA & -7.21 & -6.96 & -7.19 & -7.09 & -6.49 & -6.95 \\
1a & -8.60 & -7.90 & -7.66 & -7.81 & -7.84 & -9.10 \\
1b & -8.08 & -7.19 & -7.01 & -7.88 & -7.29 & -8.05 \\
1c & -7.80 & -7.68 & -7.54 & -8.47 & -8.23 & -9.43 \\
1d & -7.89 & -7.55 & -7.41 & -7.79 & -7.51 & -8.49 \\
1e & -7.47 & -7.50 & -7.57 & -7.63 & -7.86 & -8.25 \\
1f & -9.06 & -8.93 & -8.10 & -9.14 & -7.46 & -8.43 \\
2a & -8.80 & -9.60 & -8.39 & -9.07 & -8.05 & -8.31 \\
2b & -9.38 & -9.65 & -7.58 & -8.74 & -7.20 & -8.04 \\
2c & -9.44 & -8.87 & -9.75 & -9.24 & -8.22 & -7.94 \\
2d & -8.72 & -9.22 & -8.22 & -9.27 & -7.88 & -8.43 \\
2e & -8.69 & -9.82 & -8.17 & -8.67 & -6.34 & -8.13 \\
2f & -9.04 & -10.63 & -8.50 & -9.27 & -7.86 & -8.20 \\
\hline
\end{tabular}

* Numbers in bold are the lowest amount of binding energy value. shows that firstly, the SAHA standard ligand, and secondly, the modified ligands are in accordance with the five parameters, with the exception of the molecular weight of $2 \mathrm{f}$ ligand. We could thus infer that the ligands have successfully passed Lipinski's Rules.

The oral bioavailability of drugs could be measured by the molecular weight, number of rotatable bonds ( $n$ rotb), number of hydrogen bonds (n ON and n OHNH), and the expanse of the drug's polar surface (TPSA). This set of criteria is called Veber's rule. The oral bioavailability was marked by small molecular weight (less than

Table 6 Inhibition constant result of standard ligand docking simulation and modification towards HDAC Class II

\begin{tabular}{ccccccc}
\hline Ligand & \multicolumn{6}{c}{ Inhibition constant, Ki (nM) } \\
\cline { 2 - 7 } & HDAC 4 & HDAC 5 & HDAC 6 & HDAC 7 & HDAC 9 & HDAC 10 \\
\hline SAHA & 5160 & 7940 & 5350 & 6400 & 17600 & 8100 \\
1a & 500 & 1620 & 2430 & 1880 & 1800 & 210 \\
1b & 1200 & 5350 & 7310 & 1690 & 4560 & 1260 \\
1c & 1900 & 2360 & 7540 & 610 & $\mathbf{9 2 0}$ & $\mathbf{1 2 0}$ \\
1d & 1660 & 2920 & 63110 & 1930 & 3140 & 590 \\
1e & 3360 & 3150 & 2820 & 2560 & 1740 & 890 \\
1f & 230 & 290 & 1150 & 200 & 3390 & 660 \\
2a & 360 & 90 & 710 & 220 & 1250 & 810 \\
2b & 130 & 80 & 2760 & 390 & 5300 & 1270 \\
2c & $\mathbf{1 2 0}$ & 310 & $\mathbf{7 0}$ & 170 & 940 & 1500 \\
2d & 400 & 180 & 940 & $\mathbf{1 6 0}$ & 1680 & 670 \\
2e & 430 & 630 & 1030 & 440 & 22380 & 1100 \\
2f & 240 & $\mathbf{5 0}$ & 590 & $\mathbf{1 6 0}$ & 1730 & 970 \\
\hline
\end{tabular}

* Numbers in bold are the lowest amount of inhibition constant value. 
Table 7 The molecular descriptor value of the SAHA standard ligand and modified ligand

\begin{tabular}{|c|c|c|c|c|c|c|c|c|}
\hline Ligand & Molecular weight & $\log P$ & $n \mathrm{ON}^{1}$ & $\mathrm{n} \mathrm{OHNH}{ }^{2}$ & TPSA & $\mathrm{n}$ rotb & Drug likeness & Drug score \\
\hline SAHA & 264.325 & 2.467 & 5 & 3 & 78.42 & 8 & -8.87 & 0.35 \\
\hline $1 a$ & 288.351 & 2.391 & 6 & 3 & 80.04 & 8 & -8.5 & 0.36 \\
\hline $1 b$ & 303.366 & 1.467 & 7 & 4 & 106.07 & 8 & -10.6 & 0.1 \\
\hline $1 c$ & 294.399 & 3.022 & 6 & 3 & 80.04 & 8 & -8.17 & 0.35 \\
\hline $1 d$ & 306.341 & 2.555 & 6 & 4 & 80.04 & 8 & -9.56 & 0.35 \\
\hline 1e & 304.35 & 1.912 & 7 & 4 & 100.27 & 8 & -8.3 & 0.36 \\
\hline if & 414.247 & 3.474 & 6 & 3 & 80.04 & 8 & -8.02 & 0.29 \\
\hline $2 a$ & 407.474 & 3.306 & 8 & 4 & 109.14 & 10 & -7.4 & 0.26 \\
\hline $2 b$ & 422.489 & 2.382 & 9 & 5 & 135.17 & 10 & -9.54 & 0.07 \\
\hline $2 c$ & 413.522 & 3.937 & 8 & 4 & 109.14 & 10 & -7.12 & 0.25 \\
\hline $2 d$ & 425.464 & 3.469 & 8 & 5 & 109.14 & 10 & -8.5 & 0.24 \\
\hline $2 e$ & 423.473 & 2.826 & 9 & 5 & 129.37 & 10 & -7.23 & 0.27 \\
\hline $2 f$ & 533.37 & 4.389 & 8 & 4 & 109.14 & 10 & -6.98 & 0.17 \\
\hline
\end{tabular}

$1=$ number of hydrogen bonds

${ }^{2}=$ number of hydrogen bond acceptors

500); also, the number of rotatable bond must be less than 10, the number of hydrogen bond donors and acceptors must be less than 12, and TPSA values less than 140. Table 7 has shown that the SAHA standard ligand and the modified ligands have good oral bioavaibility, with the exception of $2 \mathrm{~b}, 2 \mathrm{~d}$, and $2 \mathrm{e}$ ligands. Those ligands are still in accordance with Veber's rule.

The hydrophobicity of drugs could be inferred from Log P value. When its value is increasing, the drug will be more hydrophobic. When the drug is more hydrophobic, then the drug will be able to circulate longer in our body, because it wouldn't be easy to secrete it. The table 7 shows, that the $\log P$ values of the $1 c, 1 d, 1 f, 2 a$, $2 \mathrm{c}, 2 \mathrm{~d}, 2 \mathrm{e}$, and $2 \mathrm{f}$ modified ligands are larger than the SAHA standard ligand. It shows that the modified ligands are more hydrophobic than SAHA. Normally, drugs, which interact with enzyme inside human body, have Log P value between 2 and 5 [11]. The table shows that only modified $1 \mathrm{~b}$ and $1 \mathrm{~d}$ ligands, which have $\log \mathrm{P}$ value less than 2 .

The drug likeness value of standard and modified ligand shows the fragment content of the drugs. If the drug likeness values are increasing, than it has the same fragment content with existing drugs. From Table 7, it is shown that the drug likeness value of $1 \mathrm{a}, 1 \mathrm{c}, 1 \mathrm{e}, 1 \mathrm{f}$, 2a, 2c, 2d, 2e, and $2 \mathrm{f}$ ligands are larger than the SAHA standard ligand. The highest drug likeness values are in 2f ligand. This result tells us, that the modified ligand has the most fragments content of drugs.

The drug score values are the combination of drug likeness, Log P, solubility, molecular weight, and toxicity risk within one useful practical value. It could be used for evaluating the potential of the drug candidate [12]. When the drug score is better, then the compound has a better chance to be a drug candidate. Table 7 shows that only modified 1a and 1e ligands have better drug score than SAHA standard ligand.

\section{Inhibitor toxicity prediction}

This research is using three different softwares to predict Inhibitor toxicity. They are Osiris Property Explorer, Toxtree v2.1.0 and Lazar. All of them have different parameters for determining the toxicity of compounds. The prediction using Osiris Property Explorer was shown in colour codes. The result of toxicity analysis of SAHA standard ligand, first, and second modified ligands is shown in table 8.

Green colour shows the low toxicity tendency, yellow shows the mediocre tendency, and red shows high tendency. Table 8 shows that only $1 \mathrm{~b}$ and $2 \mathrm{~b}$ ligands have high toxicity. This happens because they have mutagenic aniline group $\left(\mathrm{C}_{6} \mathrm{H}_{5} \mathrm{NH}_{2}\right)$. Other ligands have low or mediocre toxicity.

Table 8 Toxicity of SAHA standard and modified ligand based on Osiris Property Explorer

\begin{tabular}{ccccc}
\hline Ligand & Mutagenic & Tumorigenic & Irritant & Reproductive effective \\
\hline SAHA & yellow & green & green & green \\
1a & yellow & green & green & green \\
1b & red & red & yellow & yellow \\
1c & yellow & green & green & green \\
1d & yellow & green & green & green \\
1e & yellow & green & green & green \\
1f & yellow & green & green & green \\
2a & yellow & green & green & green \\
2b & red & red & yellow & yellow \\
2c & yellow & green & green & green \\
2d & yellow & green & green & green \\
2e & yellow & green & green & green \\
2f & yellow & green & green & green \\
\hline
\end{tabular}


Inhibitor toxicity could be verified by using Toxtree v2.10, and the result could be seen at table 9 .

Toxtree v2.1.0 determined the toxicity level of compounds based on Benigni and Bossa rules. It stipulated that certain functional groups, which have mutagenic or carcinogenic properties, could influence the toxicity. The table 9 shows that $1 \mathrm{~b}$ and $2 \mathrm{~b}$ ligands have tendency to be mutagenic, while $1 \mathrm{~d}, 1 \mathrm{f}, 2 \mathrm{~d}$, and $2 \mathrm{f}$ ligands have potential to be carcinogenic. However, when Toxtree software result was compared with QSAR analysis, only $2 b$ ligand has mutagenic potential, and $2 \mathrm{~d}$ ligand has carcinogenic potential. SAHA standard ligand and 1a, 1c, 1e, 2a, 2c, and $2 \mathrm{e}$ modified ligands were in accordance of Benigni and Bossa Rules, because they don't have potential to be mutagenic or carcinogenic.

Lazar is a software package with functionality of detecting mutagenic or carcinogenic properties based on the functional group similarity with mutagenic or carcinogenic ones. The analysis result of inhibitor toxicity by lazar could be read at table 10 .

Lazar verified the mutagenicity of compounds by conducting assay test with Salmonella typhimurium. Table 10 shows that SAHA standard, first, and second modified ligands have no mutagenic properties. Moreover, the carcinogenicity of compounds was verified by animal testing, with rodent, Rat, and Mouse. Table 10 also shows that SAHA standard ligand has no carcinogenic property toward the three animals. However, the 1e modified ligand has carcinogenic property toward rodent, $1 \mathrm{~b}$ and other second modified ligands were carcinogenic toward mouse.

Screening the best ligand based on docking and drug scan The best ligands for each class II HDACH Homo sapiens could be determined based on drug scan and docking

Table 9 Toxicity of SAHA standard and modified ligand based on Toxtree v2.1.0

\begin{tabular}{|c|c|c|c|c|}
\hline Ligand & $\begin{array}{l}\text { Negatif for genotoxic } \\
\text { carcinogenity }\end{array}$ & $\begin{array}{l}\text { Negatif for nongenotoxic } \\
\text { carcinogenity }\end{array}$ & $\begin{array}{c}\text { Potential S.Typhiurium TA } 100 \text { mutagen } \\
\text { based on QSAR }\end{array}$ & $\begin{array}{c}\text { Potential carcinogen based } \\
\text { on QSAR }\end{array}$ \\
\hline SAHA & yes & yes & no & no \\
\hline $1 a$ & yes & yes & no & no \\
\hline $1 b$ & no & yes & no & no \\
\hline $1 c$ & yes & yes & no & no \\
\hline $1 d$ & yes & no & no & no \\
\hline $1 e$ & yes & yes & no & no \\
\hline $1 f$ & yes & no & no & no \\
\hline $2 a$ & yes & yes & no & no \\
\hline $2 b$ & no & yes & yes & no \\
\hline $2 c$ & yes & yes & no & no \\
\hline $2 d$ & yes & no & no & yes \\
\hline $2 e$ & yes & yes & no & no \\
\hline $2 f$ & yes & no & no & no \\
\hline
\end{tabular}

Table 10 Toxicity analysis result by using Lazar.

\begin{tabular}{|c|c|c|c|c|c|}
\hline \multirow[t]{2}{*}{ Ligand } & \multicolumn{2}{|c|}{ Mutagenicity } & \multicolumn{3}{|c|}{ Carcinogenicity } \\
\hline & Salmonella typhimurium(CPDB) & Salmonella typhimurium(Kazius/Bursi) & Rodent(multiple sex) & Rat(both sex) & Mouse(both sex) \\
\hline SAHA & no & no & no & no & yes \\
\hline $1 \mathrm{a}$ & no & no & no & no & no \\
\hline $1 b$ & no & no & no & no & yes \\
\hline 1c & no & no & no & no & no \\
\hline $1 d$ & no & no & no & no & no \\
\hline 1e & no & no & yes & no & no \\
\hline if & no & no & no & no & no \\
\hline $2 a$ & no & no & no & no & yes \\
\hline $2 b$ & no & no & no & no & yes \\
\hline $2 c$ & no & no & no & no & yes \\
\hline $2 d$ & no & no & no & no & yes \\
\hline $2 e$ & no & no & no & no & yes \\
\hline $2 f$ & no & no & no & no & yes \\
\hline
\end{tabular}




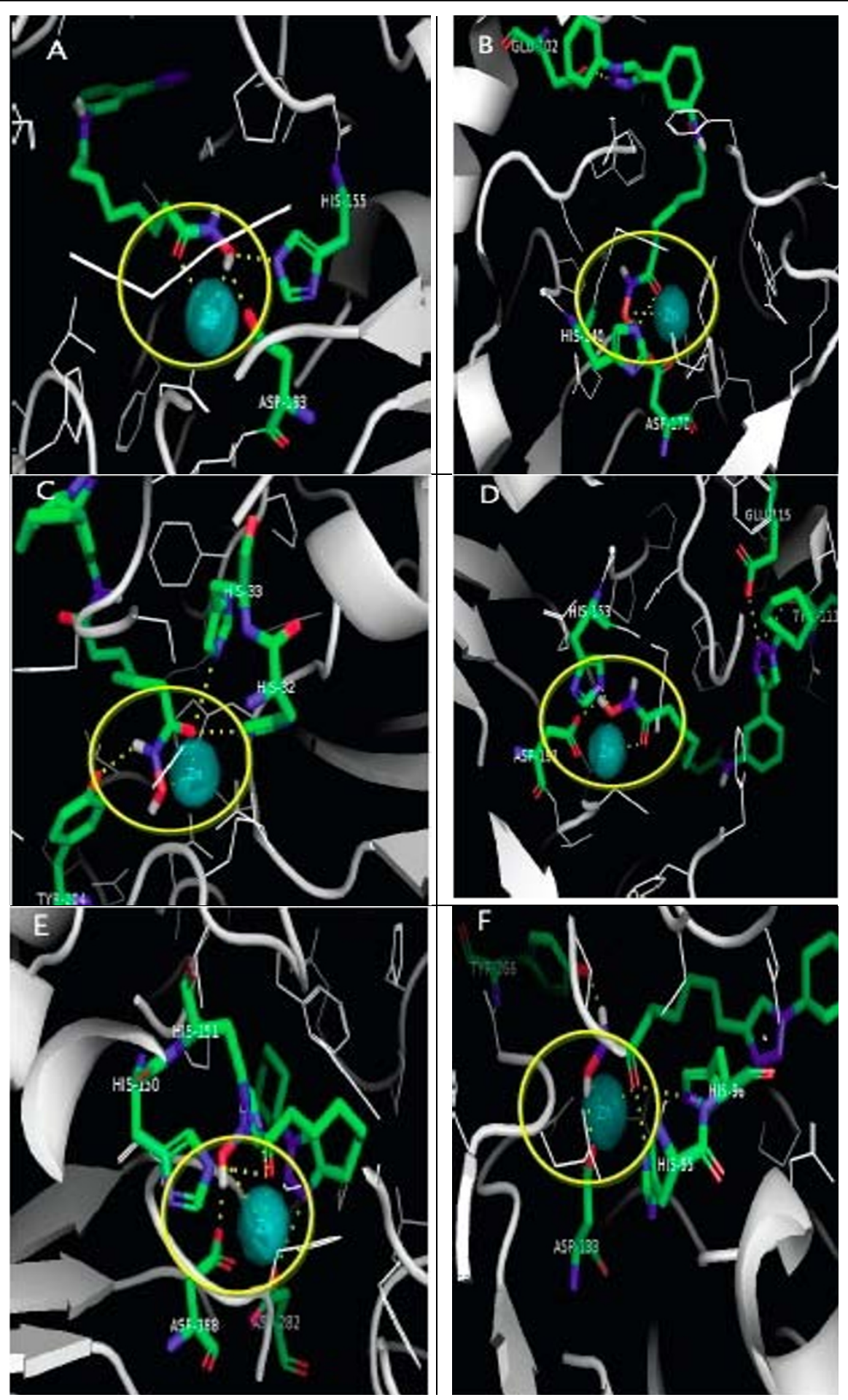

Figure 6 3D Docking simulation results. Interaction between: A. 2c ligand and HDAC 4 Homo sapiens. B. 2a ligand and HDAC 5 Homo sapiens. C. 2c ligand and HDAC 6 Homo sapiens. D. 2c ligand and HDAC 7 Homo sapiens. E. 1c ligand and HDAC 9 Homo sapiens. F. 1c ligand and HDAC 10 Homo sapiens are shown. The area with yellow circles shows the best ligand interaction with $\mathrm{Zn}^{2+}$ ion as the enzyme catalytic site.

analysis [13]. The best ligand for HDAC4, HDAC6, and HDAC7 is 2c. It is because the $\Delta \mathbf{G}_{\text {binding }}$ and $\mathrm{Ki}$ of $2 \mathrm{c}$ were the smallest compared with other ligands, with the exception at HDAC 7 . The smallest values of $\Delta \mathbf{G}_{\text {binding }}$ and $\mathrm{Ki}$ in HDAC 7 were obtained in $2 \mathrm{~d}$ and $2 \mathrm{f}$ ligand. However, $2 \mathrm{~d}$ and $2 \mathrm{f}$ ligands have bad pharmacological and 


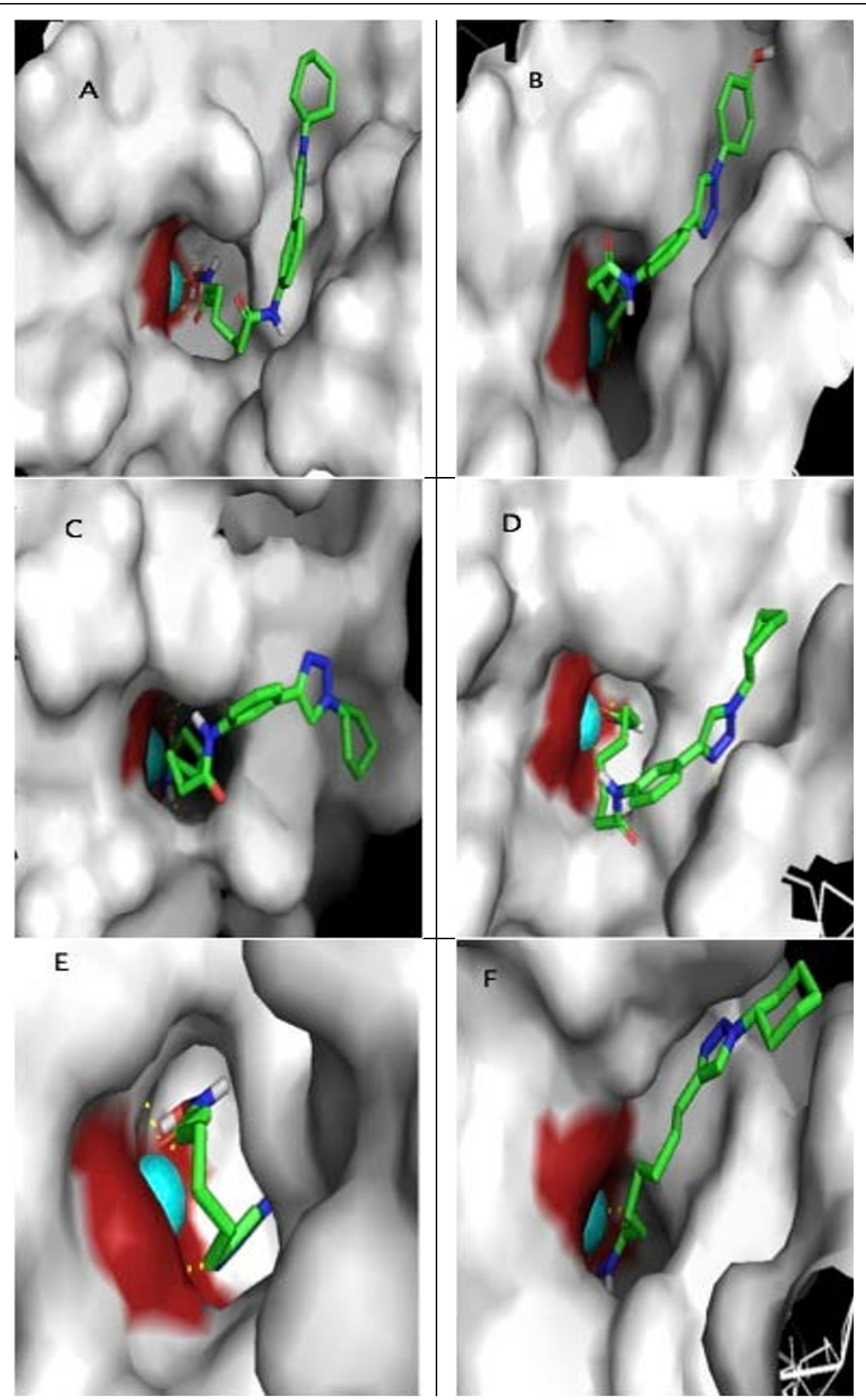

Figure 7 Surface area of ligand-enzyme interactions. Interactions are shown between A. 2c ligand and HDAC 4 Homo sapiens. B. 2a ligand and HDAC 5 Homo sapiens. C. 2c ligand and HDAC 6 Homo sapiens. D. 2c ligand and HDAC 7 Homo sapiens. E. 1c ligand and HDAC 9 Homo sapiens. F. 1c ligand and HDAC 10 Homo sapiens. These show that the cavity of enzyme is deep enough for ligand binding. The depth makes it necessary to utilize certain ligands with long aliphatic ring, in order for it to enter the cavity, and interact with $\mathrm{Zn}^{2+}$ ion. Hydrophobic cap group is necessary as well, in order to guarantee the interaction between ligand's cap groups with enzyme's surface area.

toxicity attributes, based on drug scan analysis. $2 \mathrm{f}$ Ligand is having a molecular weight, which is beyond the threshold of Lipinski's Rule parameter. Moreover, the halogen group on $2 \mathrm{~d}$ and $2 \mathrm{f}$ ligands could cause carcinogenic property on those ligands. 2c Ligand has good pharmacological attributes based on drug scan analysis, because it is in accordance of Lipinski's Rule, Veber's Rule, Log P values, toxicity, drug likeness and drug score threshold. 
The best ligand for HDAC 5 is 2a. This ligand has smaller $\Delta \mathbf{G}_{\text {binding }}$ and Ki compared with $2 \mathrm{f}, 2 \mathrm{e}$, and $2 \mathrm{~b}$ ligands. However, based on drug scan analysis, 2a ligand has better pharmacological property. The ligand is in accordance with Lipinski's rule parameter and oral bioavailability. $2 \mathrm{f}$, $2 \mathrm{e}$, and $2 \mathrm{~b}$ ligands were not in accordance to those parameters, because of its molecular weight (2f ligand), and the amount of the hydrogen bond ( $2 \mathrm{~b}$ and $2 \mathrm{e}$ ligands). Moreover, the toxicity of $2 \mathrm{f}$ and $2 \mathrm{~b}$ ligands have mutagenic and carcinogenic tendency, because of the halogen group (2f ligand) and aniline group ( $2 \mathrm{~b}$ ligand). The toxicity of $2 \mathrm{a}$ ligand is lower than $2 \mathrm{f}$ and $2 \mathrm{~b}$ ligands.

The best ligands for HDAC9 and 10 are 1c. It has the smallest $\Delta \mathbf{G}_{\text {binding }}$ and Ki compared with the others. 1c ligand has good pharmacological properties, because it is in accordance with Lipinski's Rule, Veber's rule, high hydrophobicity, and low toxicity.

The property difference among the best ligands on each class II HDAC Homo sapiens was because of the characteristic differences among those enzymes. The difference of catalytic sites of each enzyme causes the interaction tendency of ligands to be different as well.

The screening result shows that every ligand has the same alkyl group, which is cyclohexyl $\left(\mathrm{C}_{6} \mathrm{H}_{11}\right)$. 2a, 1c, 2c ligands are exceptions. The cyclohexyl group has a high tendency of hydrophobicity, and it could be seen by its log $P$ values. This matter would eventually influence the ability of the group to push the ligand for breaking in the lipid bilayer, in order for the drug to bind stronger with the enzyme. Moreover, the hydrophobic group on ligand would make the interaction between ligand and enzyme run smoothly [4].

\section{Best ligand 3D visualisation toward class II HDAC Homo sapiens}

Visualisation is the final step of SAR study. The screening result of the best ligand conformation visualization was conducted by using PyMOL [14]. The best ligand interaction toward class II HDAC Homo sapiens in 3D could be seen at figures 6 . The area with yellow circles shows the best ligand interaction with $\mathrm{Zn}^{2+}$ ion as the enzyme catalytic site. The figure 7 shows the surface area of ligandenzyme interaction, where it shows that the cavity of enzyme is deep enough. The depth makes it necessary to utilize certain ligand with long aliphatic ring, in order for it to enter the cavity, and interact with $\mathrm{Zn}^{2+}$ ion [15]. Hydrophobic cap group is necessary as well, in order to guarantee the interaction between ligand's cap groups with enzyme's surface area. Our future step to improve our validation method is by using Lead-Finder benchmarking tools. [16]

\section{Conclusions}

The docking result of SAHA standard, first, and second modified ligands toward class II HDAC Homo sapiens shows that those ligands have same type of interaction toward class II HDAC Homo sapiens, which are utilizing $\mathrm{O}$ atom on $\mathrm{C}=\mathrm{O}$ group, and its $-\mathrm{OH}$ group is binding to the $\mathrm{Zn}^{2+}$ ion. The ion is the enzyme's catalytic site. Beside, the SAHA standard and modified ligands are bonded via hydrogen bonds with amino acid residues around the enzymatic catalytic sites. Then, the analysis of $\boldsymbol{\Delta} \mathbf{G}_{\text {binding }}$ and Ki show that every first and second modified ligands have smaller $\Delta \mathbf{G}_{\mathbf{b i n d i n g}}$ and $\mathrm{Ki}$ than SAHA standard ligand. It could be inferred that every first and second modified ligand has better binding affinity than SAHA standard ligand. The complex of first and second modified ligand with class II HDAC Homo sapiens are much more preferable compared with the SAHA standard ligand.

Every modified ligand has good pharmacological properties, and it could be inferred by its accordance with Lipinskis Rule, Veber's Rule, hydrophobicity based on log $P$ value, and good drug likeness and drug score. However, $2 \mathrm{~b}, 2 \mathrm{e}$, and $2 \mathrm{f}$ ligands are exceptions. Moreover, only $1 \mathrm{a}$, $1 \mathrm{c}, 1 \mathrm{e}, 2 \mathrm{a}, 2 \mathrm{c}$, and 2e ligands have low toxicity value.

The best ligands according to the binding energy and drug scan analysis are $1 \mathrm{c}$ and $2 \mathrm{c}$ ligands, which have the same alkyl groups, the cyclohexyl $\left(\mathrm{C}_{6} \mathrm{H}_{11}\right)$. In this end, our SAR study has proven that $1 \mathrm{c}$ and $2 \mathrm{c}$ inhibitors are the best inhibitor as alternatives of SAHA.

\section{Acknowledgements}

This research is supported by Universitas Indonesia (Riset Unggulan Universitas Indonesia 2010, contract no : 2579/H2.R12/PPM.00.01 Sumber Penandaan 2010)). The authors are grateful to Ridla Bakrie Phd, for his support toward this research.

This article has been published as part of BMC Bioinformatics Volume 12 Supplement 13, 2011: Tenth International Conference on Bioinformatics First ISCB Asia Joint Conference 2011 (InCoB/ISCB-Asia 2011): Bioinformatics. The full contents of the supplement are available online at http://www. biomedcentral.com/1471-2105/12?issue=S13.

\section{Authors' contributions}

USFT supervised the research, BN was working on the technical and experimental details, AAP prepared the English manuscript; re-verified the data; and giving critical suggestion for the whole experiments.

\section{Competing interests}

The authors declare that they have no competing interests.

Published: 30 November 2011

\section{References}

1. World Health Organization: Cervical Cancer Screening in Developing Countries. Geneva: World Health Organization; 2002.

2. Tambunan USF, Parikesit AA, Tochary T, Sugiono D: In silico study of post translation modification of Chimeric vaccine design by using Virus like particles of HPV with capsid virion L1. Makara, Sains 2007, 11(2):56-62.

3. Irianiwati, Utoro T, Ediati FX: The correlation between HPV infection and p53, pRb, Kl-67 as well as tunnel expression of cervical carcinoma. Berkala IImu Kedokteran 2007, 39(3):115-121.

4. Tambunan USF, Wulandari EK: Identification of a better Homo sapiens Class II HDAC inhibitor through binding energy calculation and descriptor analysis. BMC Bioinformatics 2010, 11:7-16. 
5. Subha K, Kumar GR: Assessment for the identification of better HDAC inhibitor class through binding energy calculations and descriptor analysis. Bioinformation 2008, 3(5):218-222.

6. Dong Hoon K, Minjung K, Ho Jeong K: Histone deacetylase in carcinogenesis and its inhibitors as anti-cancer agents. J Biochem Mol Biol 2003, 36(1):110-119.

7. Roffey J: Bioisosteres in medicinal chemistry. Maybridge MedChem 1997, 1:23-44.

8. Pirali T, Pagliai F, Mercurio C, Boggio R, Canonico PL, Sorba G, Tron GC, Genazzani AA: Triazole-modified histone deacetylase inhibitors as a rapid route to drug discovery. J Comb Chem 2008, 10(5):624-627.

9. He R, He R, Chen Y, Chen Y, Ougolkov AV, Zhang JS, Savoy DN, Billadeau DD, Kozikowski AP: Synthesis and biological evaluation of triazole-4-ylphenyl-bearing histone deacetylase inhibitors as anticancer agents. Journal of Medicinal Chemistry 2010, , 53: 1347-1356.

10. Tambunan USF, Alamudi S: Designing cyclic peptide inhibitor of dengue virus NS3-NS2B protease by using molecular docking approach. Bioinformation 2010, 5(6):250-254.

11. Copeland, Robert A: Evaluation of Enzyme Inhibitors in Drug Discovery. New Jersey: Wiley Interscience; 2005.

12. Lindemann RK, Johnstone RW: Histone deacetylase inhibitors: promising candidates for chemotherapeutic drugs. Gene Ther Mol Biol 2004, 8:61-74.

13. Alonso H, Bliznyuk AA, Gready JE: Combining docking and molecular dynamic simulation in drug design. Med Res Rev 2006, 26(5):531-568

14. Difei W: Computational studies on the histone deacetylases and the design of selective histone deacetylase inhibitors. Curr Top Med Chem 2009, 9(3):241-256

15. Bottomley MJ, Lo Surdo P, Di Giovine P, Cirillo A, Scarpelli R, Ferrigno F, Jones $P$, Neddermann $P$, De Francesco R, Steinkühler C, Gallinari $P$, Carfí A: Structural and functional analysis of the human HDAC 4 catalytic domain reveals a regulatory structural zinc-binding domain. $J$ Biol Chem 2008, 283(39):26694-26704.

16. Stroganov OV, Novikov FN, Stroylov VS, Kulkov V, Chilov GG: Lead finder: an approach to improve accuracy of protein-ligand docking, binding energy estimation, and virtual. J Chem Inf Model 2008, 48(12):2371-2385.

doi:10.1186/1471-2105-12-S13-S23

Cite this article as: Tambunan et al: In silico modification of

suberoylanilide hydroxamic acid (SAHA) as potential inhibitor for class II histone deacetylase (HDAC). BMC Bioinformatics 2011 12(Suppl 13):S23.

\section{Submit your next manuscript to BioMed Central and take full advantage of:}

- Convenient online submission

- Thorough peer review

- No space constraints or color figure charges

- Immediate publication on acceptance

- Inclusion in PubMed, CAS, Scopus and Google Scholar

- Research which is freely available for redistribution

Submit your manuscript at www.biomedcentral.com/submit
Biomed Central 